\title{
APROPRIAÇÃO PARTICIPATÓRIA MEDIANTE INTERAÇÃO VERBAL POR TRÍADES DE CRIANÇAS DURANTE A RESOLUÇÃO DE PROBLEMAS MATEMÁTICOS
}

\section{Participatory appropriation through verbal interactions by triads of children during resolution of mathematical tasks in the Elementary School}

\author{
Maria do Carmo Lobato da Silva ${ }^{1}$. Marinalva Silva Oliveira ${ }^{2}$
}

Resumo: Buscou-se compreender como ocorre a apropriação de conhecimentos mediante interação verbal por tríades de crianças com e sem relação de amizade quando participam conjuntamente de tarefas matemáticas. Participaram 24 alunos da $3^{\mathrm{a}}$ série do Ensino Fundamental, agrupados em quatro tríades com relação de amizade (TCRA) e quatro tríades sem relação de amizade (TSRA). A seleção para agrupá-los nas tríades ocorreu por meio de entrevista buscando conhecer o vínculo afetivo. As interações foram registradas com filmadora e gravador, transcritas e analisadas segundo o método microgenético. Os resultados mostraram que as TCRA evidenciaram uma interação verbal mais intensa, provocando maior apropriação de conhecimentos entre os participantes do que nas TSRA. Verificou-se que um contexto cooperativo ensejou maiores possibilidades do uso de uma linguagem comum, facilitando, desta forma, o entendimento, bem como a negociação em caso de discordância entre os participantes.

Palavras-chave: Ensino Fundamental. Interação verbal. Ensino de matemática. Tríade. Amizade. Afetividade.

\begin{abstract}
This study searched to understand how the appropriation of knowledge through verbal interactions by triads of children with and without regard for friendship when they participate jointly in Mathematical tasks occurs. 24 students from the $3^{\text {rd }}$ grade of elementary school, grouped into four triads with regard for friendship (TCRA) and four triads without regard for friendship (TSRA) participated. The selection to group them in triads occurred through interview searching to know the emotional bond. The interactions were recorded with video camera and recorder, transcribed and analyzed according to a microgenetic method. According to the results the TCRA showed a more intense verbal interaction, causing a greater appropriation of knowledge among the participants than in TSRA. This way, it could be observed that a cooperative context caused greater possibilities in the use of a common language, facilitating understanding as well as negotiation in case of disagreement among the participants.
\end{abstract}

Keywords: Basic education. Verbal interaction. Mathematics teaching. Triad. Friendship. Affectivity.

\footnotetext{
* Elaborado com base no relatório final de iniciação científica (PIBIC/CNPq) "Interação verbal e construção de conhecimentos matemáticos por tríades de crianças com e sem relação de amizade no ensino fundamental", (agosto 2006-julho 2007).

${ }^{1}$ Secretaria Municipal de Educação de Santana. Avenida Joaquim Procópio de Oliveira, 1635, Bairro

Fazendinha. Macapá, AP, Brasil. carmo.lobato@yahoo.com.br

${ }^{2}$ Universidade Federal do Amapá (UNIFAP). Macapá, AP, Brasil.
} 
Silva, M. C. L.; Oliveira, M. S.

\section{Introdução}

O objetivo deste trabalho é compreender como ocorre a apropriação de conhecimentos através da interação verbal por tríades de crianças com e sem relação de amizade quando participam conjuntamente de tarefas matemáticas. A abordagem ocorrerá pelo estudo dos processos de interação entre crianças, e do modo como os fatores afetivos podem interferir e/ ou influenciar na construção de conhecimentos. O referencial de análise baseia-se nos conceitos de participação guiada e apropriação participatória de Rogoff $(1998,2005)$, que mostram como os processos de interação social podem promover mudanças qualitativas nos participantes quando atuam colaborativamente em uma atividade. Deste modo, o contexto social onde acontecem as interações não é neutro, nem limitado à ação individual, mas é construído através de interações entre os participantes (OLIVEIRA, 2002; CARVALHO, 2001).

Para Rogoff $(1998,2005)$, o contexto social é constituído por normas e práticas desenvolvidas e apropriadas pelas gerações passadas, que deixam heranças como: letramento, sistema numérico, sistema de valores e regras. Estes conhecimentos visam não só instruir práticas culturais, mas proporcionar interações sociais nas quais adultos e crianças participam. Neste sentido, a participação guiada enseja diferentes perspectivas que são colocadas à disposição do outro e da própria aprendizagem, remetendo a processos intersubjetivos que focalizam a maneira como os participantes são envolvidos num trabalho conjunto (ROGOFF, 1998, 2005). Desta maneira, a participação guiada é oferecida como um meio de olhar para todas as interações e combinações interpessoais, como: acontecimentos do dia a dia, interação direta com outro, lado a lado, longínqua, face a face, e ações incidentais. As variações e similaridades de participação em atividades culturais são responsáveis pelo desenvolvimento e aprendizagem de cada um no grupo, e esse envolvimento interpessoal provoca mudanças consubstanciais no ambiente sociocultural (ROGOFF, 2005).

No contexto da sala de aula, a participação guiada pode ser analisada durante a interação entre alunos, desde que essa interação possibilite constantes ações e comunicações verbais ou gestuais (ROGOFF, 1998). Essas ações poderão indicar a construção direta ou indireta das possibilidades de participação na atividade, indicando facilidade de envolvimento entre os participantes e, também, restrição de ações na atividade.

Seguindo a premissa de participação guiada, cada participante, no percurso de sua vida, encontra-se em contextos interacionais nos quais, através de ações mutuamente reguladas e/ou dirigidas, está continuamente coconstruindo significados ou conceitos sobre um determinado tema. Assim, os processos interativos e de comunicação, que envolvem a construção conjunta de significados, canalizam o desenvolvimento humano (VALSINER, 1996; SIMÃO, 2002).

Um dos contextos interacionais é o das interações verbais que envolvem diferentes perspectivas a serem articuladas e confrontadas, de forma a induzir às coordenações interindividuais e, subsequentemente, às coordenações intraindividuais. Estas últimas foram denominadas, por Vygotsky (2003), como internalização, isto é, a reconstrução da atividade psicológica baseada na operação com signos. O conceito tem sido apresentado em diferentes perspectivas teóricas, sendo, mais recentemente, utilizado por Rogoff $(1998,2005)$ sob o nome de apropriação participatória. Para esta autora, o participante em uma resolução de problemas se envolve num processo que está além do nível individual, pois, ao longo da interação, ao se 
beneficiar do pensamento compartilhado, o participante não extrai alguma coisa de um modelo externo, ao contrário, envolve-se diretamente na apropriação. Isto é, durante o processo, reflete sobre sua compreensão, compartilhando significados e, posteriormente, utiliza esta compreensão de uma forma individual diferente daquela construída conjuntamente. A participação guiada conduz o participante a se apropriar do conhecimento à medida que se envolve e é orientado por normas, práticas, valores e parceiros sociais (ROGOFF, 2005). Neste sentido, a apropriação participatória é o processo pelo qual os participantes, em uma dada tarefa, transformam seus conceitos e os utilizam em atividades similares, sendo um processo de abstração e generalização de conhecimentos. Portanto, aprendizado e desenvolvimento seguem variações e similaridades de acordo com a natureza da orientação e do envolvimento prático em diferentes atividades culturais.

Partindo desses pressupostos, o desenvolvimento humano é tomado como constituinte, isto é, constituído e constituidor de um contexto amplo e complexo, onde diversos fatores estão interatuando, favorecendo algumas direções no desenvolvimento biopsicossocial de cada participante (OLIVEIRA, 2002). Sob esta ótica, os processos de participação e de comunicação envolvem a construção conjunta de significados, promovendo o desenvolvimento humano, sendo orientados por transformações da subjetividade dos envolvidos na atividade (BRANCO, 2006; COSTA; LYRA, 2002). É a partir deste processo de apropriação de diversos saberes e valores que o desenvolvimento e os objetivos pessoais serão continuamente reelaborados durante a interação social, desequilibrando e reequilibrando cada participante, e fazendo surgir os processos de desenvolvimento cognitivo-afetivo.

Em situações de solução de problema, de fato, acredita-se que novas perspectivas da solução podem ocorrer de forma mais evidente quando os participantes atuam em tríades, possibilitando a confrontação de diferentes pontos de vista. Quando o outro apresenta a sua forma de pensar, sentir e agir através da verbalização, poderá gerar conflitos sociais e cognitivos (CARVALHO; CÉSAR, 2002; CARVALHO, 2005; OLIVEIRA, 2003). A partir deste conflito, cada um pode tentar e conseguir convencer o outro a aceitar seu ponto de vista e, desta forma, indicar a direção a seguir, ou pode surgir uma nova forma de abordar o problema que não estava presente antes. Essa nova forma de abordar o problema provoca a elaboração de metas, submetas que visam atingir um objetivo final, seja para convencer o outro a aceitar seu ponto de vista ou estabelecer limites para a ação do outro. Através da interação, os participantes buscam interferir cognitiva e afetivamente no outro, e esse processo enseja a construção de conhecimento em ambos os interatores (CÉSAR, 2000; NEVES; CARVALHO, 2006; OLIVEIRA et al., 2007; SIMÃO, 2000, 2002).

Enfocando a interação verbal numa perspectiva dialógico-sistêmica, esta ultrapassa sua função imediata de comunicação e troca de informações sobre uma temática, para colocála como possibilitadora da coconstrução não só de conhecimento a respeito de um tema, mas, também, da significação que, a partir daí, o participante faz da realidade. E deve ser entendida de acordo com o desenvolvimento ontogenético datado e culturalmente contextualizado, baseando-se na significação que o participante faz de si, do outro e da relação eu-outro (BRANCO, 2006; SIMÃO, 2004).

O papel relevante da interação verbal é, portanto, colocar o participante em confronto com diferentes visões de mundo, criando conflitos desequilibradores que podem possibilitar, através de maior ou menor coordenação e cooperação com o outro, a construção de novos 
significados. Esses significados serão, em parte, construídos durante a interação, podendo implicar novas ações para o alcance de uma meta (BOESH, 1991). Nessa ótica, interagir verbalmente significa compartilhar, questionar, contra-argumentar, negociar pontos de vista, enfim, envolve o processo de coconstrução de conhecimento, haja vista que, durante esse processo, os participantes tentam negociar significados e tais pontos de vista, provocando signos semelhantes na consciência do outro. Assim, a análise das interações verbais pode revelar as formas pelas quais os participantes se envolveram na tarefa, como negociaram suas estratégias, pontos de vista, e como se dá a relação eu-outro (NEVES; CARVALHO, 2006; OLIVEIRA et al., 2007).

A relação eu-outro, segundo Simão (2002, 2004), envolve aspectos afetivo-cognitivos que direcionam o envolvimento ou não dos participantes na tarefa. Neste sentido, o vínculo afetivo entre os participantes, as relações socioculturais estabelecidas durante a interação verbal, podem ser fundamentais para a presença de conflitos gerados pela atuação do outro, permitindo o autoconhecimento, regulações cognitivas e emocionais, pois a interação tem o papel de oportunizar que as crianças conheçam o outro, despertando processos metacognitivos no outro e em si mesmas (BRANCO, 2006).

Os participantes agem, assim, no sentido de interferir cognitiva e afetivamente no outro, independente do fato de terem intenção ou não sobre o que estão fazendo (BOESCH, 1991); e, essa interferência mútua, possibilitará mudanças e, consequentemente, desenvolvimento cognitivo-afetivo nos interatores. Neste sentido, esta relação de aspectos afetivo-emocionais no processo de desenvolvimento humano e da passagem do mundo concreto para o mundo das ideias, analisada durante a interação entre crianças, abre uma perspectiva para a discussão da importância das relações afetivas durante a interação verbal entre tríades de crianças.

No campo da aprendizagem matemática, pesquisas anteriores (CORRÊA; MOURA, 1997; FREITAS, 2005; SILVEIRA, 2005) têm destacado o processo de construção de conceitos e uso de estratégias aritméticas, por crianças, durante a interação professor-aluno. Entretanto, segundo Silveira (2005), cada contexto no qual a criança está envolvida permite a construção de diferentes interpretações (criação de novos conceitos), tanto das regras matemáticas quanto da própria situação em questão. Desta maneira, um contexto interacional entre crianças ou professor-aluno apresenta suas especificidades e características, permitindo alguns tipos de envolvimentos e restringindo outros, dependendo do significado que cada participante atribui ao outro e à própria tarefa que está realizando (OLIVEIRA et al., 2007; OLIVEIRA, 2002; SIMÃO, 2000).

Tudge e Rogoff (1989) ressaltam, na interação aluno-aluno, a possibilidade de os pares proverem um ao outro oportunidades para discutir, enquanto Stodolsky et al. (1984 apud FORMAN, 1989) enfatizam o valor da interação professor-aluno nas tarefas em que se destacam as instruções verbais. Assim, embora haja indicadores de que ocorre construção de conhecimento favorecido por ambos os tipos de interação, ainda não se conhecem particularidades de sua eficiência em diferentes contextos situacionais.

Assim, de maneira geral, durante a interação professor-aluno ou adulto-criança, a relação tende a ser mais de complementaridade, com uma desigual distribuição de poder, enquanto na relação aluno-aluno ou criança-criança, em que os níveis de conhecimento são similares, a distribuição de poder e/ou conhecimento tende a ser mais simétrica, gerando uma reciprocidade que pode favorecer a construção de conhecimento. 
Apropriação participatória mediante interação ...

Desta forma, a interação entre alunos tende a ser mais rica em ações verbais que a interação professor-aluno. Em estudos desenvolvidos sobre interação entre alunos, Carvalho (2005) afirma que interagir com diferentes parceiros durante a resolução de tarefas matemáticas pode envolver negociações, argumentações, contra-argumentações, conflitos sociocognitivos que não ocorreriam na interação professor-aluno; e, assim, são construídas novas possibilidades para coconstrução de conhecimentos entre os participantes da tarefa. Esta compreensão vem contribuindo para a transformação da forma de pensar o ensino e aprendizagem da matemática no contexto da sala de aula. O professor é o mediador social importante na sala de aula, mas é preciso considerar que os alunos também podem construir conhecimentos com seus pares.

Segundo Carvalho $(2001,2005)$, no contexto escolar, a ausência ou baixa competência verbal do aluno em expor seu pensamento gera, nos professores, expectativas negativas sobre seu potencial, corroborando, assim, resultados negativos. Talvez falte à escola apropriarse do conhecimento informal do aluno e organizar tarefas não habituais que representem algum desafio, que o estimulem a utilizar seus conhecimentos de forma relacional. Nesta linha, segundo Freitas (2005), a forma como a escola vem ensinando desconsidera as estratégias utilizadas pelos alunos para interpretarem os enunciados das questões, tornando dicotômicas as estratégias de ensino e aprendizagem da matemática. A reversão desse quadro é fundamental para que os alunos efetivamente possam compreender seu próprio desenvolvimento diante da tarefa.

Diante do exposto, o propósito desse estudo foi compreender como ocorre a apropriação de conhecimentos através da interação verbal por tríades de crianças, com e sem relação de amizade, quando participam conjuntamente de tarefas matemáticas.

\section{Método}

\section{Participantes}

Participaram desta pesquisa 24 alunos da $3^{a}$ série do Ensino Fundamental de uma escola da rede Pública de Macapá, agrupados em quatro tríades com relação de amizade (TCRA) e quatro tríades sem relação de amizade (TSRA).

\section{Materiais}

Os materiais utilizados para a obtenção de informações empíricas foram os seguintes: papel, lápis, borracha, filmadora digital, mini DVD para filmadora digital, minigravador e mini fita cassete.

\section{Obtenção de informações empíricas}

Inicialmente, foi realizada uma visita à escola onde foi solicitada autorização para desenvolvimento da pesquisa. Obtida a concordância da escola, foi feito contato com as professoras da $3^{\text {a }}$ série do Ensino Fundamental, para uma conversa sobre os objetivos da pesqui- 
Silva, M. C. L.; Oliveira, M. S.

sa. O propósito do contato com as professoras foi verificar quais os conteúdos de matemática que já haviam sido trabalhados na sala de aula. Participaram da obtenção de informações empíricas 24 alunos da $3^{a}$ série do Ensino Fundamental, agrupados em quatro tríades com relação de amizade (TCRA) e quatro tríades sem relação de amizade (TSRA). A seleção para agrupá-los nas tríades ocorreu através de uma entrevista, cujo propósito era conhecer sobre o vínculo afetivo com seus colegas, bem como o tempo de amizade, e se gostavam ou costumavam realizar trabalhos juntos. A partir das indicações na entrevista, foram formadas as TCRA. Já as TSRA formaram-se com os alunos que não receberam nenhuma indicação na entrevista. Posteriormente, as tríades foram encaminhadas a uma sala separada, em dias e horários diferentes, onde deveriam resolver cinco problemas matemáticos em tarefas não habituais. Tarefas essas diferentes quanto ao enunciado, mas semelhantes quanto ao aspecto conceitual sobre conteúdos já trabalhados em sala de aula. As interações entre as crianças foram registradas com o auxílio de uma câmera de vídeo e um minigravador, com o consentimento das crianças, da professora e da direção da escola. Cada tríade participou de uma sessão, e, durante a sessão, eram solicitadas às tríades de alunos que tentassem solucionar os problemas matemáticos, sempre verbalizando, para os outros participantes, as dúvidas, as estratégias e as metas utilizadas no decorrer da resolução dos problemas. Após essas explicações, foi entregue, a cada tríade, um papel com os problemas a serem solucionados por escrito, sendo colocado um lápis e um papel para rascunho à disposição dos mesmos, objetivando, desta forma, propiciar condições que pudessem provocar a realização conjunta dos problemas. Após a finalização do trabalho, as fitas foram transcritas e analisadas segundo o método microgenético. Os critérios para análise tinham o intuito de verificar como ocorria o processo de apropriação de conhecimentos através da interação verbal entre tríades com e sem relação de amizade.

Para identificação das TCRA, utilizamos TCRA1, TCRA2, TCRA3, TCRA4, enquanto, para as TSRA, utilizamos TSRA1, TSRA2, TSRA3, TSRA4. E, para identificar cada participante das tríades, utilizamos as iniciais de seus nomes.

\section{Resultados}

Para analisar as informações obtidas nesta pesquisa, foi utilizado o método microgenético. Este método apresenta as seguintes exigências próprias: (a) Observações que se estendam pelo período inteiro do início da mudança ao tempo no qual se obtém um estado relativamente estável; (b) Alta densidade de observações relativamente à taxa de mudança do fenômeno; (c) Comportamento observado submetido a intensa análise, tentativa por tentativa, com o objetivo de inferir os processos que dão origem aos aspectos quantitativos e qualitativos da mudança, uma vez que focaliza todo processo de ensino e aprendizagem (SIEGLER; CROWLEY, 1991; GÓES, 2000). Com o uso do respectivo método, permitiu um estudo minucioso de todo o processo interativo, e não apenas a análise final da interação. Desta forma, possibilitou a verificação mais detalhada: dos envolvimentos e propósitos dos participantes na tarefa, estratégias utilizadas, regulações de diferentes pontos de vistas por concordâncias e discordâncias, ou seja, uma análise mais refinada sobre como ocorreram as interações e estruturações de participação por facilitação ou restrição durante a resolução dos problemas matemáticos. 
Apropriação participatória mediante interação ...

Assim, a análise será focada na forma como cada participante se envolveu na tarefa quando tinha ou não vínculos afetivos com seus parceiros sociais, e como se apropriou dos conceitos matemáticos trabalhados na sala de aula mediante utilização de estratégias aritméticas.

\section{Tríades com Relação de Amizade (TCRA)}

\section{Participação guiada por coconstrução: TCRA1}

\section{$\mathbf{E}-\mathbf{M}-\mathbf{L}$}

Na TCRA1, em que, na entrevista, houve reciprocidade de indicação para formação da tríade, os alunos participavam de forma interativa da resolução da tarefa e construíram, assim, um ambiente que facilitava a participação mútua. Através da intensa interação verbal entre os participantes, foi estruturado um contexto de coconstrução de significados, cujo propósito de cada participante não era só apresentar o resultado final da tarefa, mas buscavam envolver-se mutuamente na tarefa, havendo, desta forma, uma linguagem comum para facilitar o processo de negociação de pontos de vistas e estratégias aritméticas.

Nesta TCRA1, a participação estava orientada por aspectos afetivo-cognitivos, uma vez que os participantes direcionavam suas ações verbais e/ou gestuais na medida em que atribuíam importância afetiva a seus parceiros sociais e à própria atividade.

Deste modo, o envolvimento da TCRA1 na atividade foi coorientada entre os participantes, pois cada integrante da tríade criou possibilidades para seus parceiros sociais regularem seus papéis e os dos outros, sendo criadas situações de participação por facilitação entre os participantes, pois interagiam intensamente na atividade matemática. Para Simão (2002), no processo de interação, o outro pode ser fonte de inúmeras experiências, tais como gratificação ou frustração, e isso dependerá do significado construído ao longo da interação. Para ilustrar a interação entre os participantes, será apresentado um trecho de como ocorreu a participação guiada por coconstrução:

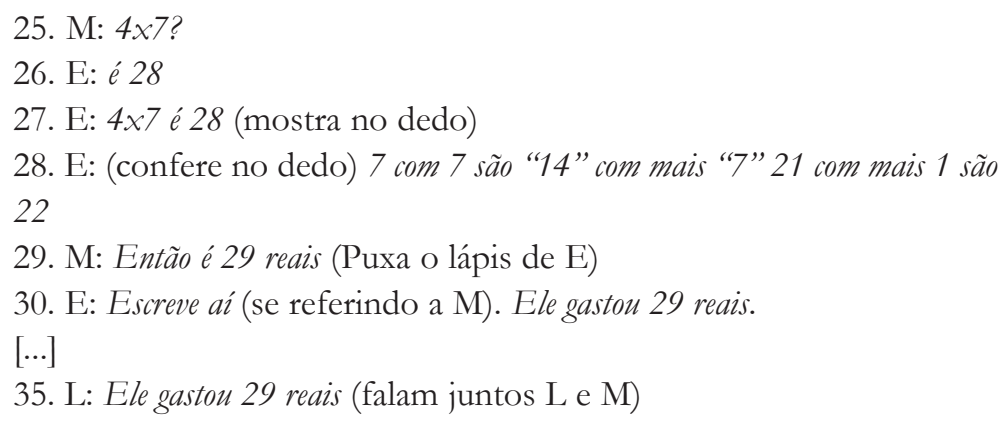

No trecho acima, E, ao perceber que L e M não compreenderam as estratégias que utilizou para chegar ao resultado final, explicou como resolveu o problema, demonstrando, nos dedos, e verbalizando a estratégia matemática, estratégia essa denominada decomposição. Dessa forma, E buscou propiciar o envolvimento de M e L na resolução da tarefa (por exemplo, na fala 28). Neste sentido, a estruturação que E fazia para envolver L e M na tarefa foi por 
Silva, M. C. L.; Oliveira, M. S.

facilitação, através da verbalização de seu raciocínio, no intuito não só de mostrar o resultado final, mas a estratégia matemática que utilizou para resolver o problema. E essa demonstração só apareceu porque E foi questionado por seus colegas da tríade. Numa situação individual não ficaria tão claro como E chegaria ao resultado. Portanto, a participação de alunos em atividades em tríades com relação de amizade é uma valiosa metodologia em sala de aula que pode promover ações verbais e gestuais ricas, implicando um maior envolvimento de todos os participantes durante a tarefa.

Diante disso, entende-se que a participação guiada nesta tríade ocorreu por coconstrução. Verifica-se que E verbaliza a estratégia que utilizou para resolver o problema acompanhado de recursos externos (contagem nos dedos), falando e mostrando, nos dedos, para que seus parceiros pudessem visualizar como havia pensado os processos que envolviam a atividade matemática. Destaca-se, nessa interação, que o propósito de E era promover o envolvimento de seus parceiros na resolução da tarefa, tanto para convencê-los que seu resultado era correto quanto serviu para alargar o potencial cognitivo de $\mathrm{M}$ e L durante a resolução; e estes, por sua vez, não demonstraram nenhuma discordância sobre as estratégias utilizada por E, ou seja, havia uma relação de confiança entre os participantes. Neste sentido suas participações direcionavam seus significados para um propósito comum, que era resolver o problema conjuntamente.

Outro momento de interação que ilustra esse contexto de participação guiada por coconstrução segue abaixo:

180. M: Não, sobrou 40,00, não vai dar para comprar isso daqui, porque a bolsa é 49,00.

182. M: Então tira a bolsa.

183. L: Tira a bolsa e compra a camisa.

184. E: (Ri) Mas ela já comprou 2 camisas.

185. M: A bolsa é mais cara.

186. L: Então compra o cinto.

187. M: O cinto é 9,00 reais.

188. E: $O$ cinto.

Nesse trecho, os participantes continuavam a se envolver mutuamente na resolução, buscando um campo comum de entendimento para comunicar e coordenar suas ideias, para que o outro pudesse compreender os processos que envolviam a tarefa - isso é identificado quando M explica para seus parceiros (falas 180 a 183). Neste sentido, pode-se afirmar que a TCRA1 caracterizou-se por uma participação guiada por coconstrução, sem que houvesse manifestação explícita de desacordos ou contradições, tendo em vista que os participantes da tríade não estavam só preocupados em resolver a tarefa, mas em envolver e explicar ao outro os processos encontrados durante a resolução da tarefa, oportunizando e facilitando, desta forma, a apropriação de conhecimentos pelo outro durante a tarefa.

Segundo Rogoff (2005), a apropriação participatória ocorre no processo de interação à medida que o participante se modifica através de seu envolvimento durante a resolução, e essa participação contribui para a direção do acontecimento em evolução e para a preparação dos participantes em outros acontecimentos similares. 
Apropriação participatória mediante interação ...

Já nas TCRA2, TCRA3, TCRA4, ocorreu a exclusão da criança com menor relação de amizade, resultando na transformação da tríade em díade. Neste sentido, a participação guiada estava relacionada aos aspectos afetivo-cognitivos que desencadeavam a coordenação de metas comuns entre os participantes, tendo em vista que um tentava estruturar por facilitação ou restrição o envolvimento do outro para atingir seus objetivos. Essa estruturação de participação ocorria na medida em que os participantes atribuíam significado de menor ou maior importância ao outro. Quando ocorria uma menor significação de amizade ao outro, havia exclusão ou uma maior limitação na tarefa. Segue um trecho para mostrar como ocorreu a participação guiada na TCRA2.

\section{Participação guiada por coelaboração: TCRA2, TCRA e, TCRA4}

TCRA2: J - B - L

114. L: (concorda com J), pois é a B tá fazendo tudo errado!

115. B: é de menos (suprimida por J).

116. J: (toma o lápis de B) vou só fazer "pá" tu "coisar".

117. J: Aqui ó (mostrando para B) 20 -2,00 reais (falam juntas B e J). (arma a conta e escreve) 0-0 é 0 [...] 0-2 quanto dá? (questiona a B) aí vai ficar quanto? ai vai ficar 10 (J começa a fazer pauzinho e confere 1, 2, 3, 4, $5,6,7,8,9,10$ ) ai tirou quanto? Ai tirou 2,00, ai ficou quanto? (conta os pauzinhos $1,2,3,4,5,6,7,8)$ ficou 8 .

118. J: Peraí, perai (B quer pegar o lápis) fica 8, aqui.

119. J: E aqui vai ficar quanto? (fala para B).

120. B: vai ficar 1 (é suprimida por J).

121. J: $1-0$ é 1.

122. J: então vai ficar 18 .

123. B: (toma o lápis de J) pois é então vai ficar 18, porque 2-1 [...]

124. J: (fica pensativa) não "peraí", "peraî" é zero isso aqui, é zero (puxa o lápis de $\mathrm{B})$.

132. L: (Pega o lápis e tenta falar alguma coisa, mas é interrompida por J)

133. J: (Puxa o lápis da mão de L) Me dá aqui!

Nesta TCRA2, ocorreu uma interação intensa, mas conflituosa, entre J e B, ou seja, a participação guiada ocorreu por coelaboração com confronto de ideias, visto que $\mathrm{B}$, ao propor uma estratégia de resolução do problema matemático, não era aceito por J, que propôs uma nova forma de resolver a tarefa através da verbalização de suas estratégias. Estes conflitos foram criados no momento em que havia esse desacordo de quem resolveria, como se resolveria e sobre os resultados dos problemas matemáticos. Durante todo o percurso da interação, houve discussões, confrontações de pontos de vista, tanto referentes à atividade quanto ao próprio comportamento das participantes (falas 115 a 120).

Os conflitos sociocognitivos eram resolvidos à medida que J verbalizava suas estratégias para que B pudesse compreendê-las (falas 117 a 122). Verifica-se que J também utiliza repre- 
sentações gráficas e gestuais para convencer B de que sua estratégia matemática estava correta. Neste sentido, apreende-se que J estrutura a participação de B na resolução do problema, pois verbalizava os processos intrassubjetivos que utilizou para resolver o problema, promovendo, desta forma, um processo de negociação e tentativa de compreensão mútua de significados. As interações verbais conflituosas foram benéficas para o desenvolvimento e aprendizagem de todas as participantes, uma vez que o desenvolvimento e aprendizagem aconteciam à medida que cada uma disponibilizava à outra os meios pelos quais encontrou o resultado, e, pelas explicações das estratégias matemáticas utilizadas na resolução dos problemas cada integrante da tríade incluía a outra na atividade, bem como, nas discordâncias, foram construídas novas formas de abordar o problema, possibilitando a construção de novas estratégias matemáticas.

Nesta tríade, ocorreu a exclusão de L na resolução da tarefa. Suas tentativas de participação mais direta foram ignoradas ou suprimidas pelas ações verbais e gestuais de J e B, sendo confirmado nas falas 132 e 133. Diante disso, verifica-se que os aspectos afetivos direcionaram o envolvimento das participantes durante a resolução dos problemas, pois suas participações foram ampliadas ou limitadas na medida em que depositavam confiança em si e na outra durante a interação.

\section{TCRA3: J - Er - E1}

Nesta tríade verificou-se que Er tinha como propósito limitar a participação de El na tarefa, e isto foi demonstrado através de frequentes ações verbais e gestuais. Assim, constatouse que esta tríade caracterizou-se por uma participação guiada por coelaboração e confronto, pois El propõe uma ideia que não é aceita por Er, que, por sua vez, expressa seu desacordo, mas, sem argumentar ou propor algo novo, também acaba buscando apoio de J, que gesticula em sinal de positivo com a cabeça (falas 111 e 112), apoiando as decisões de Er. Ao observar as interações entre os participantes, percebe-se que Er e J acabam reprimindo as argumentações de El. Para ilustrar esse momento em que El é reprimido, segue trecho:

107. Er: Agora "vamo" descobrir (põe a mão no rosto e os três ficam pensativos), "perai".

108. El: Deixa eu lê então (lê a terceira questão). Quem ficou com mais figurinhas no final do jogo? Quanto? quanto é que tinha, não, quanto a Alice perdeu? Ub caramba (Er e El puxam a mão um do outro de cima do papel) "péra lá" que essa "tô" tentando saber! (Er interrompe)

109. Er: Eu também, eu também, "né" que esta bacana? (fala para "El" e ri. Os três olham fixamente para o papel. "El" interrompe).

110. El: Olha, olha. Olha aqui, olha aí, ai tinha, tu vê, tu vê quantos a Alice perdeu, tu vê quanto ela ganhou, tu vê quanto ela perdeu, tu vê quanto ela ganhou (apontando para o papel).

111. Er: Ta doido! (põe a mão no rosto). Jogou com quem jogou né? (olhando para "J")

112. J: (balança a cabeça em sinal positivo)

113. Er: Ta vendo doido!

114. El: (sacode a cabeça em sinal positivo sorrindo e olhando para "Er") 
Apropriação participatória mediante interação ...

Quando Er não conseguia apoio nas suas decisões, utilizava atitudes e comportamentos antissociais para suprimir as ações dos outros participantes, como puxar o papel, ou mesmo impedir as tentativas de participação de El ou J utilizando termos pejorativos para provocar constrangimento e fazer com que ambos o apoiassem no resultado encontrado por ele (fala 111). Isso é observado quando El tenta explicar para Er como havia compreendido o problema (fala 110); entretanto, Er limita a participação de El no problema e faz mudar todo o percurso da interação, tentando convencer ao próprio El de que sua explicação não está correta; e, para afirmar sua posição no controle da situação, busca e consegue o apoio de J (falas 111 a 114). Rogoff (2005) chama esse processo de participação guiada por constrangimento. $O$ que permeia esse processo interpessoal são as regulações dos papéis dos outros e seu próprio papel na tarefa, onde as situações estruturadas de participação por Er limitam o envolvimento de El na resolução da tarefa, haja vista que quem direciona o percurso da resolução da atividade é o próprio Er.

Diante disso, percebe-se que as ações de Er indicavam a limitação da participação de El na tarefa, demonstrando, desta forma, que não havia uma relação de confiança de Er para El, uma vez que Er buscava o apoio de J nas suas decisões, e este, por sua vez o apoiava; portanto, infere-se que os aspectos afetivos funcionavam como possibilitadores tanto da participação por facilitação quanto pela restrição de algum participante na tarefa matemática.

\section{TCRA4: A - F - D}

Nesta tríade, ocorreu uma interação mais direta entre A e D, caracterizando-se por uma participação guiada por coelaboração por consentimento, sem que houvesse manifestações de desacordos. Nesta TCRA4, observa-se que houve um envolvimento mútuo entre A e D, onde uma possibilitava a participação da outra na tarefa por facilitação, conforme as falas:

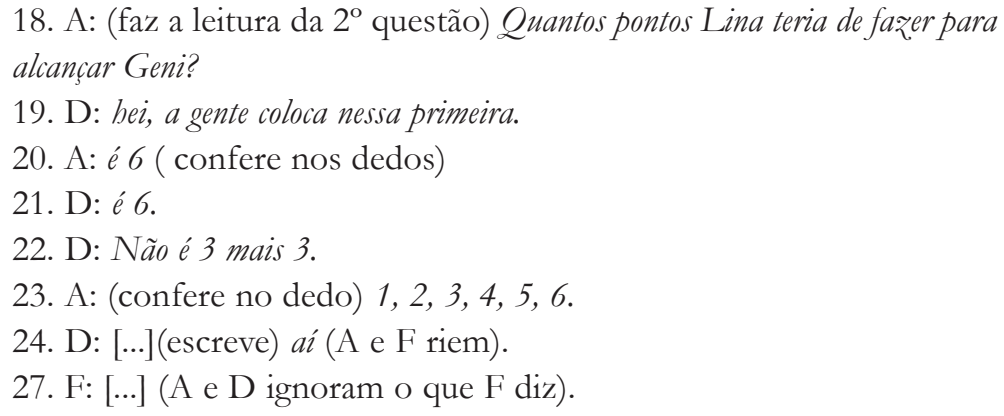

Observa-se que F pouco verbalizava o que pensava sobre a tarefa ou outro assunto, e, em sua tentativa de participação mais direta, foi ignorada pelas outras participantes (fala 27). Entretanto $\mathrm{F}$ parecia observar atentamente o que A e D faziam, e suas ações não indicavam nenhuma discordância nas decisões de A e $\mathrm{D}$ sobre os processos e resultados da resolução do problema.

A díade $\mathrm{A}$ e $\mathrm{D}$ estabeleceu uma relação de cooperação, ensejando maior intersubjetividade nos processos cognitivo-afetivos, visto que ambas estavam envolvidas diretamente na resolução do problema, pois criavam possibilidades de participação uma da outra na tarefa. Isto é verificado quando verbalizavam e demonstravam, através dos dedos, as estratégias utili- 
Silva, M. C. L.; Oliveira, M. S.

zadas para resolver a atividade (falas 18 a 23). Diante disso, verifica-se que o propósito de A e $\mathrm{D}$ era o de alcançar sucesso na tarefa e ampliar suas participações durante a atividade, e houve pouca discordância quanto aos processos e resultados dos problemas matemáticos. Já $\mathrm{F}$ pouco participou da tarefa, e, quando tentava participar, era ignorada pela díade A e D.

\title{
Tríades sem relação de Amizade (TSRA)
}

Já nas tríades sem relação de amizade, verificou-se que as ações verbais e/ou gestuais dos participantes não tinham como propósito envolver o outro na tarefa, mas restringir sua participação. Desta forma, os participantes pouco discutiam sobre os processos que envolviam a resolução dos problemas, ou seja, o que se percebia é que não havia relação de confiança e, consequentemente, havia pouco envolvimento entre os participantes.

TSRA1: V - A - J e TSRA2: J - L - W

Nas TSRA1 e TSRA2, os participantes buscaram resolver os problemas competitivamente, tendo como meta alcançar objetivos individuais, o que, em suas ações, expressavam comportamentos antissociais, como puxar o papel e o lápis do outro, como tentativa de impedir a participação do outro na tarefa.

TSRA1

\author{
16. J: Tá demorando! (Puxa o lápis e o papel para si) o leão tem quanto \\ mesmo? \\ 17. A: O leão... \\ 18. J: O leão tem...., 50 o leão? \\ 19. V: Uh...caramba! [...] \\ sou bom de matemática. \\ 22. J: "Perai otário" me solta! \\ 23. V: Tu juras que vai resolver só tu! \\ 24. J: 5, 10 (Apontando para o papel). Achei a resposta. \\ 25. V: Hum... muito fácil, beim..beim.
}

Nesta tríade, verifica-se um contexto de competição entre os participantes, não havendo negociação ou discussão sobre os processos que envolviam a tarefa. Compreende-se que o propósito do participante $\mathrm{V}$ é apresentar o resultado final do problema de forma individual, para mostrar aos outros que sabia resolver a questão (falas 21 a 23). Na fala 18, J demonstra querer colaborar na resolução da tarefa, mas $\mathrm{V}$ tenta impedir a ação de J (fala 21), entretanto J encontra sozinho o resultado da questão (fala 24). Diante do comportamento dos participantes, percebeu-se um contexto de disputa de quem resolveria a tarefa. E quando o resultado foi encontrado por J, este não verbalizou quais estratégias utilizou para resolver o problema; e $\mathrm{V}$ não questiona o resultado e ainda tenta colocar em dúvida o potencial cognitivo de J quando afirma que a resolução é muito fácil. 
Apropriação participatória mediante interação ...

\section{TSRA2: J - L - W}

Esta tríade também caracteriza-se por um contexto de competição entre as participantes, sendo verificadas ações como puxar o papel e o lápis para si na tentativa de resolver individualmente. Diante disso, percebe-se que ambas as participantes não demonstravam ter uma relação de autoconfiança sobre seu potencial cognitivo, e mostravam também pouca relação de confiança cognitiva e afetiva nas outras parceiras, isso é percebido nas seguintes falas e ações:

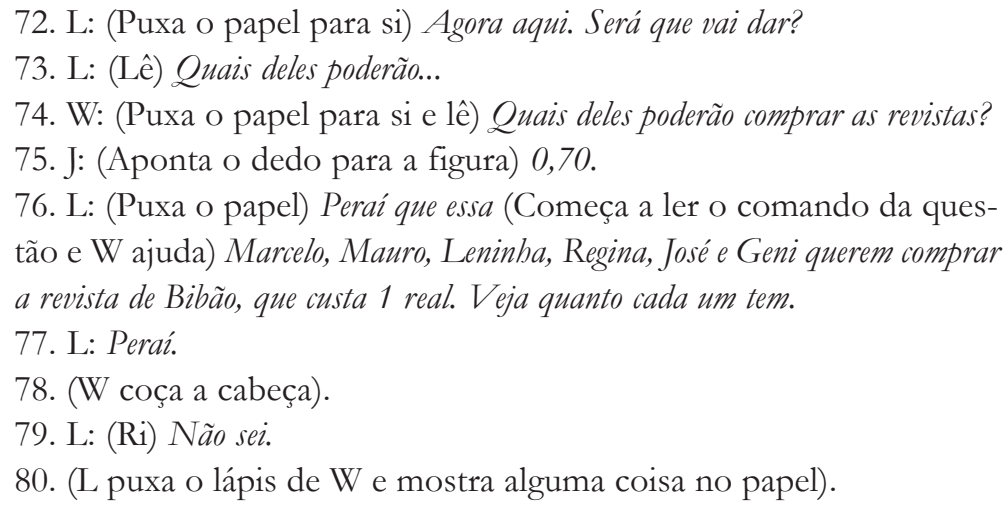

Nesta tríade, ocorreram indícios de uma participação guiada baseada na competitividade, pois cada participante buscava alcançar seu próprio objetivo na tarefa, não possibilitando, desta forma, o envolvimento mútuo. Uma relação de competição se caracteriza quando um participante se aproxima de seus objetivos e o outro se distancia das possibilidades de alcançálos (falas 72 a 76). As ações de puxar a atividade e o lápis da mão indicaram uma relação em que não havia confiança entre as participantes, portanto o papel de cada uma no grupo era individual e competitivo.

\section{TSRA3: H - S - E e TSRA4: E - I - A}

Os participantes das outras TSRA3 e TSRA4 resolveram os problemas de forma individual, com pouca interação verbal, tendo em vista que cada um na tríade buscava afirmar seu potencial de ação diante da tarefa; mas, ao perceberem que a meta não seria alcançada por essas ações, solicitavam participações restritas dos outros visando apoio às suas decisões. Assim, ocorreu participação guiada com restrição.

\section{TSRA 4}

10. A: (Lê com dificuldade a questão) para pintar a casa de cerca de plantas...

11. E: (Interrompe e lê com rapidez e alto) Para pintar a casa com cerca de plantas o pintor gastou 8 latas de tinta ...Tá aqui escreve.. (Aponta para o papel).

12. A: (Escreve) [...] 
Silva, M. C. L.; Oliveira, M. S.

19. I: (Fica em pé e põem os antebraços sobre a mesa e começa a ler) A casa de tijolo gaston 3 latas de tinta.

20. E: (Interrompe e começa a ler mais rápido que I) $A$ menos que a casa de cerca de plantas.

21. E: Tá aqui (Apontando para o papel) gastou 5 latas.

As ações de interromper, ler mais rápido e apresentar apenas o resultado final para os demais participantes indicaram que E buscava estruturar a participação de A e I de forma limitada, onde estes apenas apoiassem suas decisões diante do resultado final da resolução do problema. Segundo Rogoff (1998), a estrutura de participação por facilitação ou limitação é definida tanto pela cultura como por parceiros sociais, e estes, por sua vez, têm consonância com propósitos expressos durante as interações. Neste caso, o propósito de E era afirmar seu potencial cognitivo para seus colegas através da resolução individual da tarefa. Neste sentido, observa-se que o participante que estava resolvendo o problema não envolvia os outros na tarefa e desta forma não permitia que os companheiros do grupo tivessem acesso a suas estratégias de resolução (falas 20 e 21). Diante disso, verifica-se que, em situações individuais, cada participante persegue e obtém seus próprios resultados.

\section{Discussão}

Os processos de interação de tríades de alunos aqui estudados se caracterizam pela maior ou menor interação verbal e envolvimento dos participantes durante a resolução de problemas matemáticos, e estas participações foram variadas e similares. Cada ação verbal e/ ou gestual do participante direcionava para propósitos comuns ou individuais, logo, o contexto no qual aconteceram as interações não foi neutro em relação ao desempenho dos participantes na tarefa, nem tão pouco restrito ao ambiente físico e social onde as interações aconteceram e se modificaram à medida que a própria interação foi acontecendo. Rogoff (2005) enfatiza que o desenvolvimento individual acontece à medida que as pessoas participam e contribuem em atividades culturais, à vista disso, elas próprias se desenvolvem a partir de seu envolvimento na atividade.

Desta maneira, verificou-se que, na TCRA1 em que a intervenção do outro foi mais frequente, com ações verbais e/ou esforços para compreender as ações dos outros, foram possibilitados maiores compartilhamentos de significados entre os participantes da tarefa. Nesta perspectiva, a aprendizagem só pode ocorrer na relação eu-outro quando cada participante desperta em si e nos outros processos internos de desenvolvimento (VYGOTSKY, 2003; SIMÃO, 2002).

Nesta linha, a participação guiada nas TCRA conduziu o participante a se apropriar do conhecimento à medida que se envolvia e era orientado por parceiros sociais sobre o desenrolar da atividade. Deste modo, infere-se que somente a participação de alunos numa determinada atividade não significa o compartilhamento de significados e apropriação de conhecimentos (isto pôde ser mostrado nas atitudes das TSRA que buscavam resolver os problemas de forma competitiva ou individual); portanto, a maneira como cada aluno se envolve ou 
é envolvido pelo outro na tarefa interfere decisivamente para a criação de um contexto social, e este contexto tem diferentes significados, como: cooperativos, competitivos e individuais.

Os resultados mostraram que o tempo de interação verbal das tríades TSRA foi inferior ao das TCRA, permitindo inferir um grau de intersubjetividade maior onde o vínculo afetivo foi maior. A afetividade significou maior coordenação social entre parceiros e, consequentemente, direcionamento para objetivos comuns.

Neste contexto, infere-se que o afeto foi importante na aprendizagem e no desenvolvimento cognitivo, como propulsor de interação verbal. Segundo Neves e Carvalho (2006), a afetividade impulsiona o desenvolvimento cognitivo, fortalecendo-se com as estruturas construídas e direcionando a atividade intelectual. Assim, as TCRA se envolveram em interações mais intensas de acordo com a relevância que atribuíram um ao outro para propósitos coletivos ou individuais. Importância essa conectada com experiências construídas anteriormente e trazidas para a relação. Enquanto, nas TSRA, as estruturações de participação eram restritas, tendo em vista que os participantes diminuíam as oportunidades de verbalizar suas estratégias matemáticas ou restringiam as ações verbais e gestuais dos outros com atitudes antissociais, que visavam limitar ou, mesmo, excluir a participação do outro durante a tarefa.

Por conseguinte, a interação foi mais consistente e a participação guiada ocorreu mais intensamente entre tríades que tinham relação de amizade, principalmente onde houve reciprocidade de indicação, na entrevista, sobre os vínculos de amizade (TCRA1). Nas demais TCRA (TCRA2, TCRA3, TCRA4), onde a indicação não foi mútua, apesar de se transformarem em díades durante a resolução da tarefa, ainda assim, a discussão e envolvimento entre os participantes ocorreram de forma intensa, com o propósito de construir conhecimento, e assim revelaram as formas pelas quais os participantes, durante a resolução da tarefa matemática, negociaram suas estratégias, pontos de vista e sobre como chegaram ao resultado final. Ao regularem e estruturarem suas ações e as dos outros, os participantes das TCRA2, TCRA3, TCRA4 construíram e compartilharam significados que os conduziram a modificar seus comportamentos, buscando, assim, alcançar um objetivo coletivo.

Deste modo, em um contexto cooperativo, onde são estruturadas as relações de confiança no parceiro, são maiores as possibilidades do uso de uma linguagem comum que venha facilitar o entendimento, assim como a negociação em caso de discordância. Assim, as interações verbais são instrumentos de facilitação importante para a construção de conhecimento, pois revelam formas pelas quais os participantes, durante a resolução da tarefa matemática, compartilharam suas estratégias, construíram seus conceitos matemáticos, negociaram e interpretaram as regras matemáticas (OLIVEIRA, 2002; SILVEIRA, 2005).

Outro ponto importante, que merece ser destacado, é o de que houve diferenças significativas na maneira como as estratégias matemáticas foram utilizadas entre as TCRA e TSRA. Nas TCRA, os participantes sempre verbalizavam ao outro quais as estratégias que estavam utilizando para chegar aos resultados. Segundo Simão (2004), este envolvimento mútuo ocorre em função da representação que o participante tem de si, do outro e a relevância atribuída à tarefa. Neste sentido, percebeu-se que a interação foi mais intensa e a participação guiada ocorreu mais frequentemente nas tríades com relação de amizade. A intersubjetividade foi maior onde o vinculo afetivo era mais estreito, inferindo-se, também, que a presença frequente de diferentes estratégias, nestas tríades, estava associada à apropriação de conceitos matemáticos construídos em diferentes oportunidades que lhe foram colocadas à disposição. 
Já nas TSRA, as estratégias mais utilizadas foram as não-algorítmicas, sobretudo estratégias que envolviam cálculo mental. Nestas tríades, os cálculos eram realizados de forma individual, com pouca ou nenhuma verbalização da estratégia para o outro. Ou seja, o participante que estava resolvendo o problema não envolvia o outro na relação, de forma a não permitir que o outro tivesse acesso as suas estratégias de resolução da tarefa. Rogoff (2005) enfatiza que a criança, ao resolver individualmente uma tarefa, não deixa de estar participando de uma atividade culturalmente orientada, que envolve desde interações com os professores e os colegas de sala, até com os autores e com a editora dos livros escolares, ou seja, a participação por si só em atividades é um processo social e individual.

Entretanto, numa relação em tríades, o vínculo afetivo entre os participantes é importante na aprendizagem e no desenvolvimento cognitivo, como propulsor de interações verbais, visto que a imagem que a criança tem de si e do outro, assim como o grau de confiança que deposita em si e no parceiro, interfere no processo de construção de conhecimento e na própria participação na tarefa, uma vez que as ações deixam de ser limitadas pelos outros e passam a ser possibilitadoras de interações sociais. Portanto, a intersubjetividade está ligada à maneira como a pessoa se envolve e é envolvida num trabalho conjunto, permitindo um envolvimento interpessoal.

Desse modo, a relação entre tríades de crianças pode ser intensa e proveitosa, na medida em que, nos processos de participação, um possa envolver o outro durante a resolução da tarefa, e isso está relacionado ao significado afetivo que o outro tem para ele e para a própria atividade (OLIVEIRA, 2002; SIMÃO, 2004). O envolvimento entre parceiros sociais em que o outro tem um significado singular são ensejadas possibilidades de trocas de pontos de vista e de verbalizações sobre os processos de resolução com uma ou diferentes estratégias. Desta maneira, a explicação da trajetória até determinado resultado é benéfica para o desenvolvimento de competências tanto de quem argumenta quanto de quem contra-argumenta ou, simplesmente, observa o que os outros fazem (CARVALHO, 2005; OLIVEIRA, 2002).

Diante desses resultados, entende-se que não basta colocar os alunos em tríades ou díades para interagirem verbalmente. É preciso construir um ambiente cooperativo em que os participantes tenham vínculos afetivo-cognitivos com seus parceiros sociais. Cada aluno na tríade ou díade precisa ter significado no processo de interação, e, durante a interação verbal, surgirão possibilidades de negociar diferentes pontos de vista, com propósito de ampliar as competências matemáticas, linguísticas, sociais, cognitivas e afetivas, implicando mudanças qualitativas no desenvolvimento de ambos.

\section{Considerações finais}

Os resultados apresentados neste trabalho mostraram que a interação verbal entre pares ocorreu onde os participantes tinham vínculo estreito de amizade. $O$ vínculo de amizade possibilitou interações verbais mais intensas. Nesta ótica, quando os participantes têm a oportunidade de negociar estratégias e discutir sobre os processos que envolvem a tarefa, são obrigados a descentrar-se das suas posições pessoais para compreenderem outras formas de 
Apropriação participatória mediante interação ...

resolução e explicá-las. O conflito sociocognitivo está presente quando o participante tem a possibilidade de interagir com diferentes parceiros sociais e, assim, negociar diferentes conceitos matemáticos construídos em distintos contextos que participou (CARVALHO; CÉSAR, 2002; SILVEIRA, 2005).

Nas TCRA, foi constatado que cada participante desempenhou um papel de "guia" na apropriação de conhecimento pelo outro, já que suas ações de verbalizar, explicar e demonstrar as estratégias, auxiliavam no processo de construção de conhecimento, bem como oportunizavam que cada participante da tríade pudesse acompanhar todo o processo de desenvolvimento da atividade. Assim, foram construídas novas formas de abordar os problemas, que não estavam presentes antes, e que foram à tona a partir da interação verbal.

Alguns fatores, como o reduzido distanciamento entre o desenvolvimento cognitivo dos participantes, a confiança no outro e em si mesmo, a empatia e a história de relacionamento entre as crianças, interferiram e influenciaram claramente na intensidade da interação verbal durante a resolução das tarefas, indicando sua importância no processo de desenvolvimento.

Já nas TSRA, a maioria dos cálculos foi realizada de forma individual ou competitiva, com pouca ou nenhuma verbalização das estratégias matemáticas entre os parceiros sociais. Ou seja, o participante que estava resolvendo o problema não estruturava a participação do outro na relação e, desta forma, não permitia que o mesmo tivesse acesso a suas estratégias matemáticas.

Diante disso, a organização escolar precisa estar atenta a todos os aspectos que são fundamentais para que ocorra a interação entre os alunos e trabalhar no sentido de valorizar a educação enquanto um processo de construção conjunta, oportunizando, aos mesmos, a criação de contextos permeados de interação verbal, como forma de facilitar e ampliar conhecimentos que não ocorreriam individualmente. Nesse sentido, a construção de um contexto cooperativo possibilita, aos participantes, construírem significados conjuntos com maiores envolvimentos, discussões, argumentações, contra-argumentações, e isso, sem dúvida, é benéfico não só para o desenvolvimento de competências matemáticas, mas sociais, afetivas, cognitivas e linguísticas. Assim, cada participante passa a regular e autorregular suas ações e as dos outros para atingir um objetivo final que pode ser modificado no processo de interação.

Sob esta perspectiva, percebe-se que só a junção de alunos em tríades ou díades em tarefas matemáticas não é suficiente para que estes possam se envolver na interação. O significado que o outro e a própria tarefa têm para cada participante são fundamentais para a construção de um contexto cooperativo. Neste contexto, os objetivos que os participantes perseguem estão estreitamente vinculados entre si, de maneira que cada um pode alcançar os próprios objetivos se apenas os outros alcançarem os seus. Assim, os resultados que cada um da tríade persegue são igualmente benéficos para os demais com quem está interagindo.

Os resultados deste estudo e de outros nesta mesma linha podem ser úteis na criação de condições mais efetivas de aprendizado e desenvolvimento da criança no que se refere tanto à educação matemática quanto as relações interpessoais, pessoais e culturais, viabilizando uma maior compreensão do comportamento dos alunos e, consequentemente, desenvolvendo uma prática pedagógica voltada para a formação de atores mais participativos e capazes de relacionar os diversos conhecimentos nas situações do ambiente escolar e do cotidiano. 
Silva, M. C. L.; Oliveira, M. S.

Agradecimentos

Agradecimentos ao apoio do CNPq, aos professores da escola, pela acolhida, e, em particular, aos alunos, por sua valiosa participação na pesquisa.

\section{Referências}

BOESCH, E. E. Symbolic action theory and cultural psychology. Berlin: SpringerVerlag, 1991.

BRANCO, A. U. Crenças e práticas culturais: co-construção e ontogênese de valores sociais. Pro-Posições, São Paulo, v. 17, n. 2, p. 139-155, 2006.

CARVALHO, C.; CÉSAR, M. Interacções sociais, desenvolvimento cognitivo e matemática. In: CONGRESSO DA SOCIEDADE PORTUGUESA DE CIÊNCIAS DA EDUCAÇÃO, 5., 2002, Algarve. Actas... Porto: Colibri; SPCE, 2002. p. 407-416.

CARVALHO, C. Comunicações e interações sociais nas aulas de matemática. In:

NACARATO, A.; LOPES, C. (Ed.). Escrituras e leituras na educação matemática. Belo Horizonte: Autêntica, 2005. p. 15-34.

Interaçção entre pares: contributos para a promoção do desenvolvimento lógico e do desempenho estatístico no $7^{\circ}$ ano de escolaridade. 2001. $531 \mathrm{f}$. Tese (Doutorado em Educação) - Faculdade de Ciências, Universidade de Lisboa, Lisboa, 2001.

CÉSAR, M. Interacções sociais e apreensão de conhecimentos matemáticos: a investigação contextualizada. In: PONTE, J. P.; SERRAZINA, L. (Ed.). Educação matemática em Portugal, Espanha e Itália: actas da escola de verão em educação matemática - 1999. Lisboa: Sociedade Portuguesa de Ciências da Educação, 2000. p. 5-46.

CORRÊA, J.; MOURA, M. L. S. A solução de problemas de adição e subtração por cálculo mental. Psicologia: reflexão e crítica, Porto Alegre, v. 10, n. 1, p. 71-86, 1997.

COSTA, E. V.; LYRA, M. C. D. P. Como a mente se torna social para Bárbara Rogoff? A questão da centralidade do sujeito. Psicologia: reflexão e crítica, Porto Alegre, v. 15, n. 3, p. 637-647, 2002.

FORMAN, E. A. The role of peer interaction in the social construction of mathematical knowledge. International Journal of Educational Research, Oxford, n. 13, n. 1, p. 55-70, 1989. 
Apropriação participatória mediante interação ...

FREITAS, M. B. A. Problemas de adição e subtração: soluções em diferentes circunstâncias. 2005. 80 f. Dissertação (Mestrado em Educação) - Universidade Federal do Paraná, Curitiba, 2005.

GÓES, M. C. R. A abordagem microgenética na matriz histórico-cultural: uma perspectiva para o estudo da constituição da subjetividade. Cadernos Cedes, Campinas, v. 20, n. 50, p. $9-25,2000$.

NEVES, M. C.; CARVALHO, C. A importância da afectividade na aprendizagem da matemática em contexto escolar: um estudo de caso com alunos do $8^{\circ}$ ano. Análise Psicológica, Lisboa, v. 24, n. 2, p. 201-215, 2006.

OLIVEIRA, M. S. Construção de conhecimento em interações verbais durante solução de problemas matemáticos: uma análise semiótico-construtivista. Ciência, Educação e Cultura, Macapá, v. 1, n. 1, p. 25-50, 2003.

OLIVEIRA, M. S. Interação verbal e construção de conhecimento por díades de crianças: uma análise segundo a concepção boeschiana de "valor visado" e "valor real". 2002. 176 f. Tese (Doutorado em Psicologia) - Instituto de Psicologia, Universidade de São Paulo, São Paulo, 2002.

OLIVEIRA, M. S. et al. Participação guiada e afetividade entre crianças: um estudo comparativo entre tríades e díades. In: CONGRESSO NORTE-NORDESTE DE PSICOLOGIA, 5., 2007, Maceió. Anais... Maceió: Conselho Regional de Psicologia, 2007.

ROGOFF, B. A natureza cultural do desenvolvimento humano. Porto Alegre: Artmed, 2005.

Observando a atividade sociocultural em três planos: apropriação participatória, participação guiada e aprendizado. In: WERTSCH, J.; JAMES, P.; DEL RÍO, A. A. (Org.). Estudos socioculturais da mente. Porto Alegre: Artmed, 1998. p. 123-142.

SIEGLES, R. S.; CROWLEY, K. The microgenetic method: a direct means for studying cognitive development. American Psychologist, Washington, v. 46, n. 6, p. 606-620, 1991.

SILVEIRA, M. R. A resolução de sentidos e construção de conceitos na relação ensino/aprendizagem da matemática. 2005. 176 f. Tese (Doutorado em Educação) Faculdade de Educação, Universidade Federal do Rio Grande do Sul, Porto Alegre, 2005.

SIMÃO, L. M. Interação verbal e construção de conhecimento: desenvolvimento a partir da teoria da ação simbólica de Ernst Boesch. In: CONFERÊNCIA DE PESQUISA SOCIOCULTURAL, 3., 2000, Campinas. Caderno de resumos... Campinas: Ed. da Unicamp, 2000.

SIMÃO, L. M. O significado da interação verbal para os processos de construção de conhecimento: proposta a partir da óptica boeschiana. In: LEITE, S. A. (Org.). Cultura, cognição e afetividade: a sociedade em movimento. São Paulo: Casa do Psicólogo, 2002. p. 85-102. 
Silva, M. C. L.; Oliveira, M. S.

SIMÃO, L. M. et al. (Org.). O outro no desenvolvimento humano: diálogos para a pesquisa e a prática profissional em psicologia. São Paulo: Pioneira Thomson Learning, 2004.

TUDGE, J. R. H.; ROGOFF, B. Peer influences on cognitive development: piagetian and vygotskian perspectives. In: BORNSTEIN, M.; BRUNER, J. (Org.). Interaction in human development. Hillsdale: Erlbaum, 1989. p. 17-40.

VALSINER, J. Co-constructionism and development: a socio-historic tradition. Anuario de Psicología, Barcelona, n. 69, p. 63-82, 1996.

VYGOTSKY, L. S. A formação social da mente. 6. ed. São Paulo: Martins Fontes, 2003.

Artigo recebido em 19/10/11. Aceito em 11/07/2012. 